\title{
External Factors Affecting Budget Utilization in Ethiopian Public Universities
}

\author{
Dejene Taffa \\ Madda Walabu University, Ethiopia
}

\begin{abstract}
Inefficient higher education budget utilization has been adversely affecting the implementation of government policies, programs and project implementation in Ethiopia. This study sought to investigate external factors that affect proper budget utilization in public universities of Ethiopia in 2017. A total of 178 respondents were randomly selected from Dilla, Wolaita Sodo, and Bule Hora Universities. Primary data were collected using closed and open questionnaires. To supplement the survey result secondary data were collected from a federal general auditor. The data were analyzed using various descriptive statistics. The findings indicated a significant improvement in budget allocation to public universities from time to time. However, imposition of the federal agencies to implement unplanned activities by Universities, delay in project implementation, low financial and technical capacity of the contractors in terms of financial and technical matter that cause project implementation delay's particularly for construction projects had adversely affected the budget utilization of the study Universities. This study recommended that the potential of the contractor both technical and financial capacity and their past performance should be properly evaluated before coming to an agreement. The result also suggested that there should be a need timely and continuous follow up the progress of the project and take corrective action before the end of the fiscal budget year.
\end{abstract}

Keywords: Budget Utilization, Public Universities, External Factors, Ethiopia

DOI: $10.7176 / \mathrm{JESD} / 10-21-06$

Publication date: November $30^{\text {th }} 2019$

\section{INTRODUCTION}

The budget refers to a plan relating to a definite future period of time expressed in monetary and/or quantitative terms. Budget is the most widely used and highest rated management tool of cost reduction and control. It is a tool that helps managers in planning and control functions (Arora 2010). However, the relative strength of each function depends on the current view of the function of budgeting and budgeting tools and techniques, but also depends on the strength of particular organizations and/or institutional arrangements to support these functions (World Bank, 1998). Governments and other public authorities are required to support the universities by allocating a huge amount of budget in order to accomplish their mission.

Budgets are based on forecasts and forecasting cannot be an exact science. Absolute, accuracy, therefore is not possible in forecasting and budgeting. The strength or weakness of the budgetary control system depends to a large extent, on the accuracy with which estimates are made. Thus, while using the system, the fact that the budget is based on estimates must be kept in view. This indicates that if there is no good estimate during the future budget judgment, overestimation or underestimation will happen which leads to overutilization or underutilization than the approved budget that's going on most public institutions (Arora 2010).

The financial management function of the Federal Government of Ethiopia is regulated by the Federal Government of Ethiopia Financial Administration Proclamation No. 57/1996. The proclamation clearly outlines the budgetary process and prescribes clear authority and relationship. Accordingly, the Ministry of Finance and Economic Cooperation (MoFEC) issued directives and regulations required for proper implementation. The financial calendar outlines responsibility, procedures and time frames for each phase of the budget cycle (FDRE. 2009).

Currently, the annual budget formulation process has two dimensions: the identification of priorities and goals, and the allocation of and management of funds. The budget formulation process has four stages: the planning stage, the budget preparation stage, the budget legislation, and budget implementation and control stages (World Bank 1998).

There are many factors why the approved budget deviated from the actual expenditure during the budget year. The causes are may differ from organization to organization by their nature.

According to Omitoogun and Hutchful (2006), there are a number of factors that can explain why actual expenditure deviates from the levels approved at the beginning of the financial year in any sector. The reasons for deviations may vary over time. Some of the more common causes are a deviation in aggregate expenditure, reallocation of funding during budget implementation, policy changes during the year, an inability to implement policies, programs and projects, and a lack of financial discipline.

During any fiscal year, even when project implementation is in progress, there could be strenuous circumstances that could compel the government to make budgetary adjustments. These circumstances could range 
from unforeseen economic shocks that lead to a shortfall in budgetary resources to unexpected windfall gains in additional resource, and delays in the implementation of projects which have slow implementation pace due to lengthy external procurement procedures which would force MoFEC to reallocate funds from such areas to projects that can be implemented quickly (Alemayehu and Dawit, 2011).

Due to the above factors, a supplemental budget could be introduced in the event that new sources of budgetary support are identified; budget reallocations are made due to delays of project implementation in one sector and better performance in others sector, curtailing expenditure in the event of shortfalls in projected budgetary resources.

According to the report of the auditor general of Ethiopia, most public higher education institutions are frequently stated as prime government institutions for indecorous utilization of the budget during the fiscal year. For example, in the year 2013/2014 budget, from only 99 public organizations over 2.576 Billion Ethiopian Birr was returned back to the treasury having not been utilized and most of this amount is from public higher education, For instance, more than 782 million Ethiopian Birr was returned back from only four public universities. Such an amount of financial resource returned affects the project implementation process as well as the realization of goals of budget. Further, more than 235 million Ethiopian Birr was over-utilized in 37 public organizations and also higher education institutions have a lion share; for instance, more than 85 million Ethiopian Birr was over-utilized in only four public universities (Federal Auditor General report, 2013/2014). Obviously, such improper budget utilization in public universities significantly affects the economic development of the county and hinders the achievement of the mission of public universities. To minimize the revealed improper budget utilization, clear identification of major external factors significantly aggravating proper budget utilization is very crucial. According to the available literature, little is known about external factors affecting budget utilization in higher public universities particularly in that of Ethiopia. Therefore, this study was aimed to identify the major external factors significantly affecting budget utilization in selected four Ethiopian public universities.

\section{Conceptual Framework}

As outlined in the figure below, the variables included in the left-hand side, affect the dependent variable in budget utilization in the public universities. It is presumed that the forecasted independent variables affect budget utilization in the Ethiopian public higher education institutions.

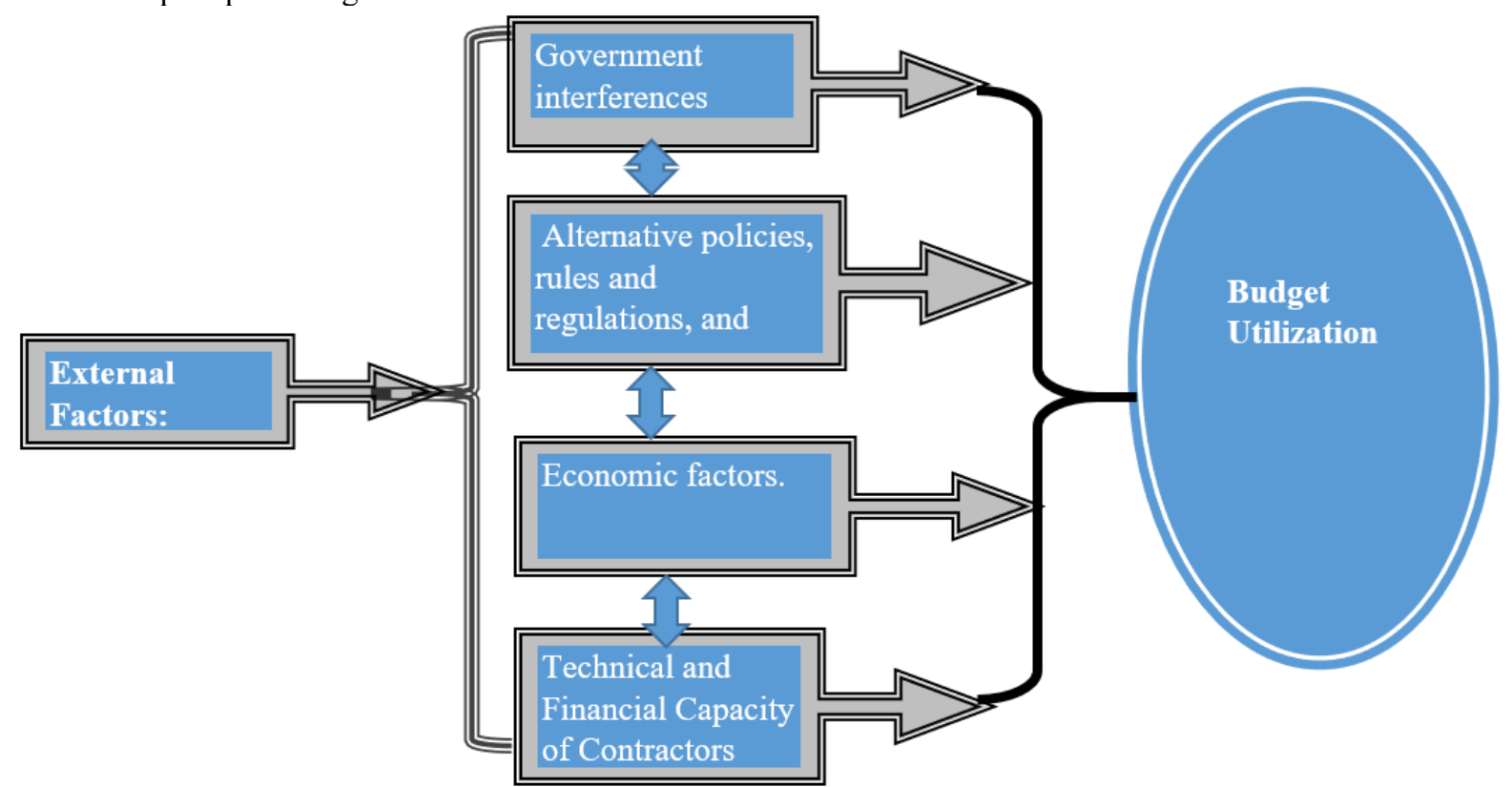

Figure1: Conceptual framework adapted from the reviewed literature by a researcher (2017)

\section{RESEARCH METHODOLOGY}

\section{Research Design}

This study used a cross-sectional survey approach. The research design is mainly descriptive. A cross-sectional study was used to determine the interrelationship between the variables under consideration among three universities in the study. This permitted us to make statistical inferences on the broader population and generalize the findings to real-life situations and thereby increase the external validity of the study. This design enabled the researcher to collect the quantitative data, where; the researchers will explain the external factors that affecting budget utilization in the study public universities. Hence, quantitative data were collected using questionnaires. 


\section{Types and Sources of Data}

Based on the objective of the study, both primary and secondary data were collected. Primary data were collected directly from respondents such as University planning and program experts, finance and procurement department, school directors, department heads, project coordination offices of the target universities and internal audit experts. Secondary data were collected from the Ministry of Finance and Economic Cooperation (MoFEC), federal auditor general office, from books, manuals, auditor annual reports, proclamations, and regulations. In addition to this, nine employees were interviewed to obtain data that cannot be explained in the structured questionnaires.

\section{Sampling Technique and Sample Size}

Currently, there are 42 public universities in Ethiopia. The Universities are categorized under four generations while, 10 universities are clustered under the first generation, 12 universities classified under the second generation, 11 universities under the third generation and the remaining 9 Universities under fourth generations. Ministries of education have organized all the universities into four major clusters. Among that southeastern cluster is where the current research focused on. The research has taken one university from each generation on the basis of the simple random sampling method. Stratification was made based on the clusters of universities and the fourth generation Universities are excluded from the sample because of that they are new and yet not face such types of problems. From every four strata, a random selection of proportionate samples was done.

There are several approaches to determine the sample size. In this study, the following Slovin's sampling formula was adopted using a 95\% confidence level.

$$
\mathbf{n}=\frac{\mathbf{N}}{1+\mathbf{N}(\mathbf{e})^{2}}
$$

Where: $\mathbf{n}=$ sample size,

$\mathbf{N}=$ Population size $=282$, and

$\mathbf{e}=$ sampling error/level of precision $=5 \%$

The above formula has followed two stages. The first step: Simple Random Sampling technique was employed, using the formula:

$$
\mathbf{n}=\frac{\mathbf{N}}{\mathbf{1 + N}(\mathbf{e})^{\mathbf{2}}} \quad \mathrm{n}=\frac{282}{\mathbf{1 + 2 8 2 ( \mathbf { 0 . 0 5 } ) ^ { \mathbf { 2 } }}}=165.4 \sim 165
$$

However, based on the three sampling techniques (Namely: Cluster sampling, stratified sampling, and simple random sampling) used for this research, the researcher considers the design effect of at least 1.5 To this effect, the researcher applied a correction formula to arrive at a representative sample size:

$$
\mathrm{n}=\frac{\mathrm{N}}{1+\mathrm{n} / \mathrm{N}}=\frac{282}{1+165 / 282}=177.9 \sim 178
$$

\section{Data Collection Methods}

The primary data was collected through open-ended and closed-ended questionnaire. The open questions require encouraging respondents to share as much information as possible in an unconstrained way while the closed-ended questionnaire involves "questions" that can be answered by simply checking a box from a pre-determined set of responses. The questionnaire was structured in such a way that it captures the respondents' profile and data pertinent to study objectives.

Unstructured interviews were conducted by selecting stakeholders and experts such as university Finance and budget directorate directors and team leaders, project coordinators, internal auditors, anti-corruption experts, economists and accounting teachers from the Universities. As they have direct interaction with the public universities in the country as well as anti-corruption directors and experts and transformation office from selected universities. This is because they are the ones well experienced with budgeting procedures in public universities. The data enumerators were administering the primary data collection by distributing the questionnaires.

Secondary data were collected from the ministry of finance and Economic Cooperation and Federal Auditor General. In addition, secondary data were collected from other related reference books and statistical bulletin prepared by different organizations.

\section{Data Analysis Methods}

The data collected was analyzed using descriptive statistics. To these effects, depending on the nature of basic research questions and data collected, descriptive statistics namely percentage, frequencies, mean and standard deviation were used to analyze the data collected by questionnaire. For the qualitative data analysis, the data collected through the interview was organized and followed by coding, and then by categorizing based on their similarities and differences. Finally, the categorized data were analyzed, interpreted, concluded and presented qualitatively through paraphrasing and narrative discussion of the participants' opinions. 


\section{RESULTS AND DISCUSSION}

\section{Trends in Budget Utilization}

According to secondary Data obtained from the report of the auditor general of Ethiopia, over utilized and underutilized budget by different government organization is significantly increasing from 2007- 2009 E.C and most public higher education institutions are repetitively listed as major government organizations for excess/under budget use and unlawful and/or improper utilization of the budget during the stated fiscal years.

According to this report, in the 2014/2015 budget year, from 110 government organizations, more than 1.955 Billion Ethiopian Birr was returned back to the treasury having not been utilized and in the year 2015/2016 and $2016 / 2017$, underutilized amount of budget by the different organization is raised to 5.056 Billion and 6.778 Billion Ethiopian Birr respectively. As the report indicated, Most of this underutilized budget was a finding from public higher education. For instance, in the 2014/2015 more than 850 million Ethiopian Birr which returned back to the treasury was from public universities and also in 2015/2016 and 2016/2017, the report of auditor general f indicates that more than 681 Million and 1.557 Billion Ethiopian Birr was returned back to treasury respectively. Such an amount of funds returned affects the project implementation process as well as the realization of objectives.

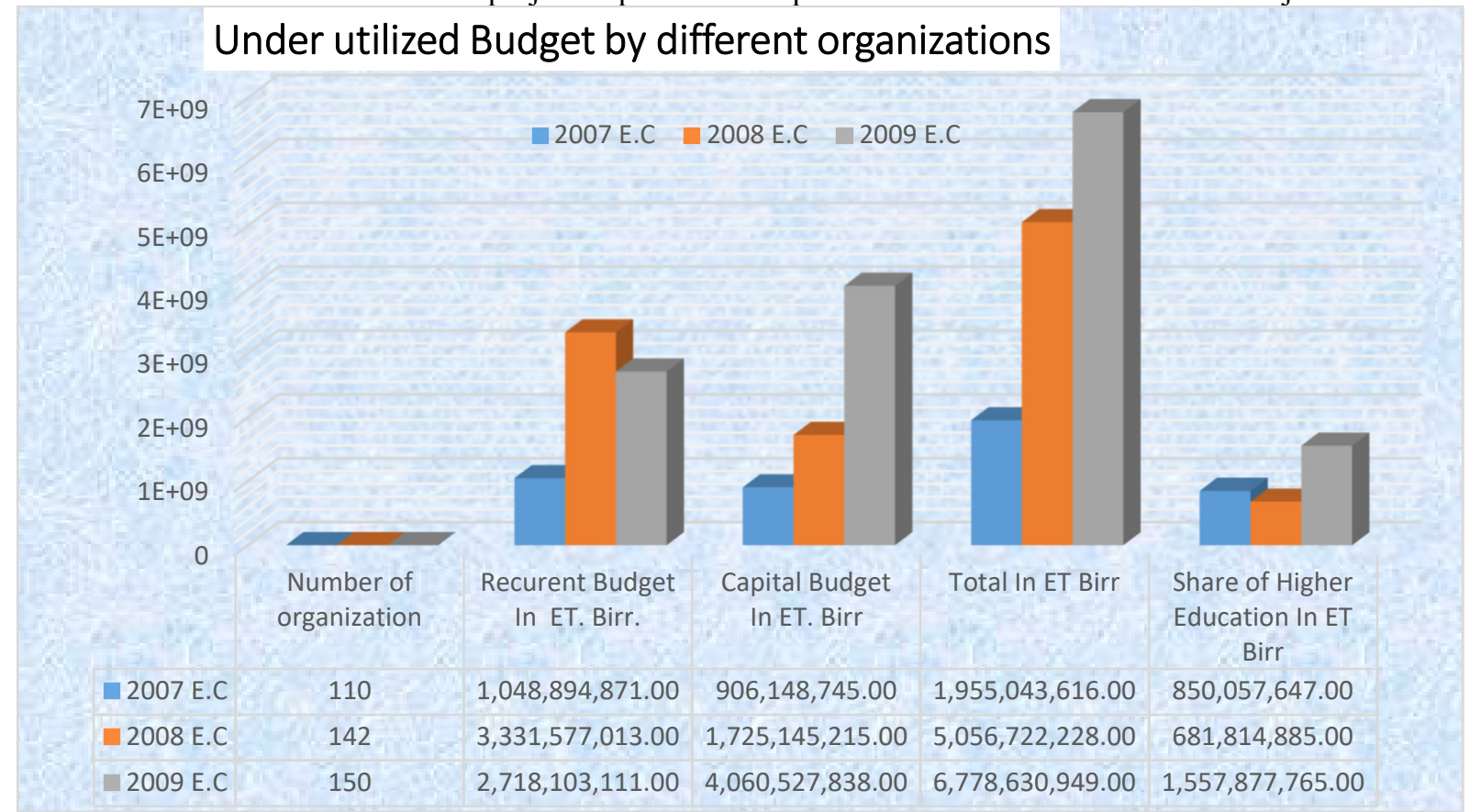

Source: Report of Federal Auditor General of Ethiopia, 2015-2017

Moreover, as it can be seen from the graph below, in the 2014/2015 fiscal budget year, more than Birr 746 million was over-utilized in 41 public organizations and in the year 2015/2016 and 2016/2017, the amount of over utilized budget finding recorded was 269 Million and 898 Million Ethiopian Birr respectively. From this over utilized amount of budget also, higher education institutions have a lion share; for instance, in the year 2014/2015, more than 331 million Ethiopian Birr was over-utilized in public universities (Federal Auditor General Report, 2014/2015). Obviously, such improper budget utilization in public universities significantly affects the economic development of the county and hinders the achievement of the mission of public universities. To minimize the revealed improper budget utilization, clear identification of major external factors significantly aggravating proper budget utilization is very crucial. 


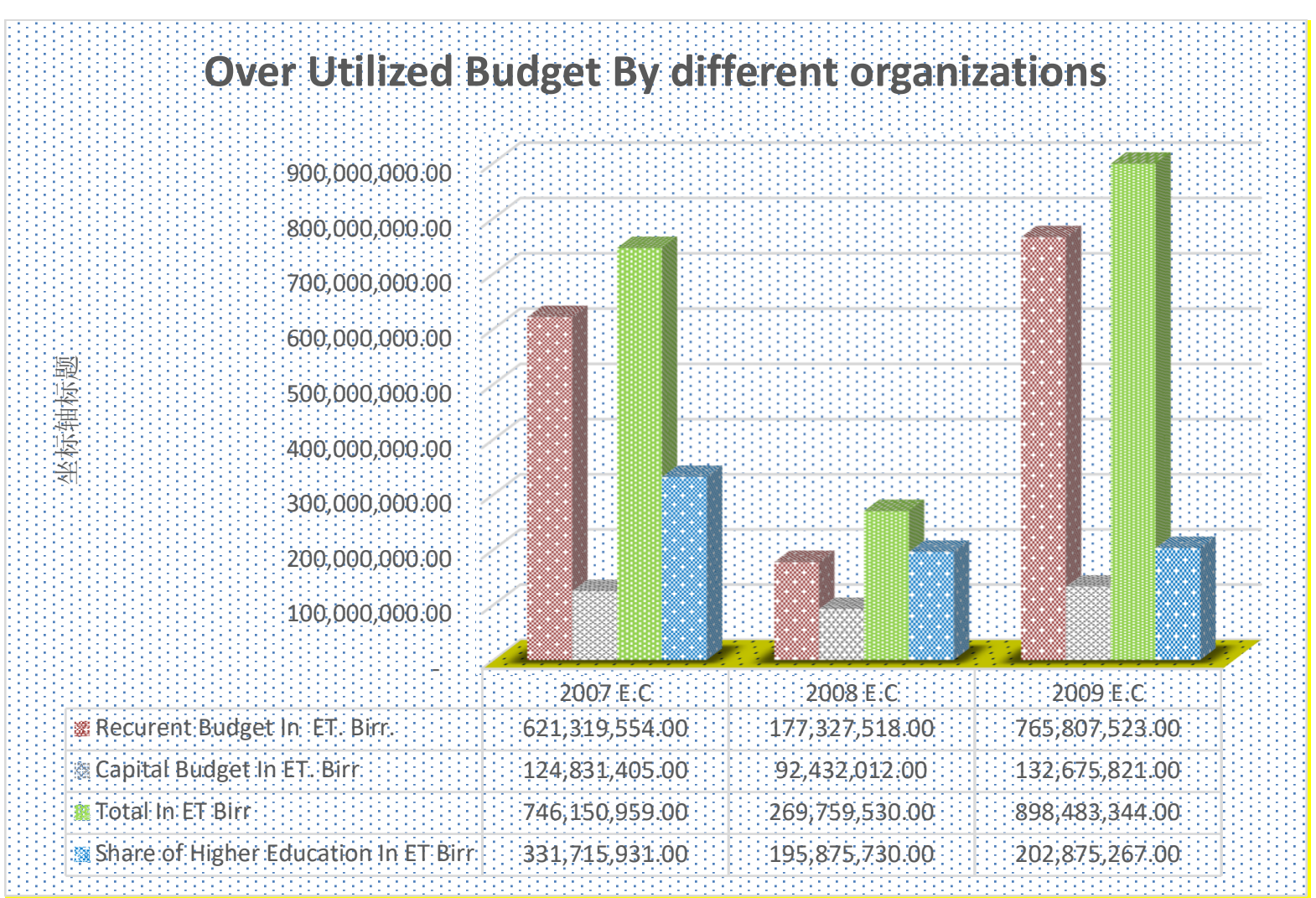

Source: Report of Federal Auditor General of Ethiopia, 2015-2017

2. Perception Level of Respondents towards External factors affecting budget utilization.

The following section is intended to assess the perception level of respondents towards external factors affecting budget utilization in public Universities. For this purpose, descriptive statistics (mean and standard deviation) were employed to assess the issue, which was measured using the Five-Point Likert Scale. According to Motwani, et al. (2014) and Pongsena (2014) the resulted mean scores were classified in ranges to fit the five-scaled Likert level of agreement (strongly disagree, disagree, neutral, agree, and strongly agree).

Table 1: Mean Score Range for Five-Scale Likert

\begin{tabular}{|l|l|}
\hline Response Mean & Level of Agreement \\
\hline From 1.00 to 1.80 & Strongly Disagree \\
\hline From 1.81 to 2.60 & Disagree \\
\hline From 2.61 to 3.40 & Neutral \\
\hline From 3.41 to 4.20 & Agree \\
\hline From 4.21 to 5.00 & Strongly Agree \\
\hline
\end{tabular}

Source ;(Motwani, et al., 2014; Pongsena, 2014)

Based on Table 1, respondents level of agreement on each item for all variables under study were determined as follows with descriptive statistics (mean and standard deviation)

3. Descriptive Analysis of External Factors Affecting budget Utilization in Public Universities

The external factors ${ }^{1}$ influencing the university budget utilization can be categorized into two parts: The major and minor factors. In this research, the major factors refer to the variables which have a strong influence with high mean value as per the respondents rating

The study sought to establish the level which respondents agreed to statements in table 2. From the findings majority of the respondents On the bases of the mean values of the respondents rating agreed that lack of unplanned activities enforced by the federal government affect budget utilization in public universities (statement 1) as shown by a mean value of 3.97 and standard deviation of 0.982 (less than 1.00) which revealed that their level perception was close to each other. The study further revealed that respondents agree on the delay in project construction which is associated with delays of procurement procedure affects budget utilization (statement 2) as shown by a mean value of 4.35, low financial and technical capacity of the contractors (statement 3 ) by a mean value of 4.28 , Raise in price of goods and services in the fiscal year affect budget utilization in Universities (statement 7) by a mean value of 3.47. However, it has been evidenced that respondents neither agree nor disagree with statements $4,5,6$ and 8 with a mean value of $2.71,2.79,3.10$,

\footnotetext{
${ }^{1}$ are factors surrounding an organization that influences its activities and choices and determine its opportunities and risks.
} 
and 3.12 respectively. As it has shown in table 2, on statements 4,5,6 and 8 their level of agreement is with a standard deviation of greater than 1.00 which revealed that their perception has differed from one another.

Table 2: Descriptive Statistics of Major External factors affecting Budget utilization in public universities

\begin{tabular}{|c|c|c|c|c|c|c|c|c|}
\hline Variables & & 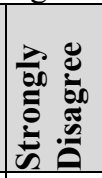 & 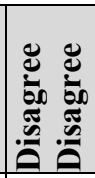 & 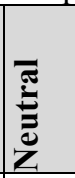 & 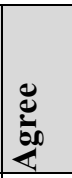 & 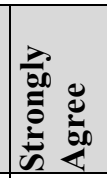 & 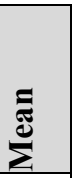 & ن \\
\hline \multirow{2}{*}{$\begin{array}{l}\text { Unplanned activities dropped from government affects } \\
\text { budget utilization in public universities }\end{array}$} & $\mathrm{N}$ & 4 & 25 & 18 & 81 & 50 & \multirow{2}{*}{3.97} & \multirow{2}{*}{0.982} \\
\hline & $\%$ & 2.2 & 14.0 & 10.1 & 45.5 & 28.1 & & \\
\hline \multirow{2}{*}{$\begin{array}{l}\text { Delay in implementation of project contractors by } \\
\text { universities affects budget utilization }\end{array}$} & $\mathrm{N}$ & 2 & 5 & 12 & 86 & 73 & \multirow{2}{*}{4.35} & \multirow{2}{*}{0.794} \\
\hline & $\%$ & 1.1 & 2.8 & 6.7 & 48.3 & 41.0 & & \\
\hline & $\mathrm{N}$ & 1 & 4 & 29 & 90 & 54 & \multirow{2}{*}{4.28} & \multirow{2}{*}{0.777} \\
\hline & $\%$ & 0.6 & 2.2 & 16.3 & 50.6 & 30.3 & & \\
\hline \multirow{2}{*}{$\begin{array}{l}\text { 4. Unstable government policies from one fiscal year to } \\
\text { another affect budget utilization }\end{array}$} & & 37 & 47 & 41 & 37 & 16 & \multirow{2}{*}{2.71} & \multirow{2}{*}{1.060} \\
\hline & & 20.8 & 26.4 & 23.0 & 20.8 & 9.0 & & \\
\hline \multirow{2}{*}{$\begin{array}{l}\text { 5. Governmental interference on the annual plans affects its } \\
\text { implementation }\end{array}$} & $\mathrm{N}$ & 20 & 64 & 46 & 37 & 11 & \multirow{2}{*}{2.79} & \multirow{2}{*}{1.099} \\
\hline & & 11.2 & 36.0 & 25.8 & 20.8 & 6.2 & & \\
\hline \multirow{2}{*}{\begin{tabular}{|l} 
6. Regulations set by MoFEC to transfer budget from one \\
program to another program
\end{tabular}} & $\mathrm{N}$ & 8 & 48 & 60 & 42 & 20 & \multirow{2}{*}{3.10} & \multirow{2}{*}{1.063} \\
\hline & $\%$ & 4.5 & 27 & 37.7 & 23.6 & 11.2 & & \\
\hline \multirow{2}{*}{$\begin{array}{l}\text { 7. Raise at the price of goods and services in the fiscal year } \\
\text { affect budget utilization in Universities }\end{array}$} & $\mathrm{N}$ & 16 & 30 & 58 & 42 & 32 & \multirow{2}{*}{3.47} & \multirow{2}{*}{0.916} \\
\hline & $\%$ & 9 & 16.8 & 32.6 & 23.6 & 18.0 & & \\
\hline \multirow{2}{*}{$\begin{array}{l}\text { 8. Way of transfer budget from one budget code to another } \\
\text { code affect budget utilization }\end{array}$} & $\mathrm{N}$ & 8 & 40 & 70 & 43 & 17 & \multirow{2}{*}{3.12} & \multirow{2}{*}{1.010} \\
\hline & $\%$ & 4.5 & 22.5 & 39.3 & 24.2 & 9.5 & & \\
\hline Iajor External Factors (Overall & & & & & & & 1 & 0.962 \\
\hline
\end{tabular}

Source: Researcher's computation using SPSS (2016)

Because of their significant impacts, the aforementioned major factors are adequately described as follows.

As can be seen from table 2 above, delay in project execution ${ }^{1}$ was the top most important factor affecting budget utilization with the highest mean value of 4.35 . The low capacity of the contractors to complete the intended projects with the given time was found to be the second most important factor with the mean value of 4.28. Topdown influences of the unplanned activities from external government institutions like MoE was found to be the third major factor affecting higher education budget utilization with the mean value of 3.97. According to the response obtained from the finance department, these activities have often dropped for implementation after the total budget allotted for the fiscal year was approved by MoFECE, and hence affects budget utilization in public universities.

Almost all respondents ( $89 \%$ ) agree that the delay of the project implementation by the contractors due to various reasons affects the budget utilization in their respective institutions. About $73 \%$ of the respondents agree with the statement that unplanned activities dropped from government affects budget utilization in public universities. Similarly, of the total of 178 respondents 144 employees have agreed that the financial and technical capacities of the project contractors have contributed a negative effect on the budget management and utilization in the study universities. This result was supported with the information obtained from the key informant interview (KIIs). According to the KIIS, inability of potential supplies to hand over the materials as per the agreement made under the bid document at the end of annual fiscal year, deducting proposed budget during reviewing process, the influence of foreign policies (the world market price), and the way of transferring the planned budget from program to program and from activities to the other activities was reported as another major factor affecting the budget utilization. While unstable government policies from one fiscal year to another and external Governmental body interference on the annual plans are the lowest cause reason which affects budget utilization with the mean value of 2.71 and 2.79 respectively.

\section{Conclusion}

This article intends to identify external factors affecting public budget utilization in the three selected universities in Ethiopia. They include Bule Hora, Dilla, and Wolayta Sodo universities. Underutilization and overutilization of public budgets in these and other higher universities in Ethiopia was one of the major challenges of higher education in Ethiopia. This is a major enthusiasm to carry out this study. Primary data were gathered from the head of the finance departments, planning heads and other experts who had deep knowledge and practical experience

\footnotetext{
${ }^{1}$ The Project Execution and Control Phase is the part of the project and product lifecycle where the tasks that build the deliverables are executed. The Project Execution and Control Phase begins when the project plan is approved and the resources necessary for executing the starting task are assembled. Project execution should be in accordance with the approved project plan. Project execution and control consist of task execution, measuring project progress, reporting project status, and exercising management controls.
} 
on budget planning, implementation, and administration. A questionnaire was distributed to resource persons in the organization whose activity is directly related to finance, project management and budget and planning departments. The data from the resource persons such as directors and school heads were gathered through a scheduled interview. The study has demonstrated that the selected three universities are suffering from lack of experience in project management, program budget preparation, and implementation. The study found that various external factors affect budget utilization in the study universities. The study researcher concluded that the external causes for miss-utilization of public budget are mainly due to delay in implementation of the project by contractors in the universities, Unplanned activities like unplanned training dropped from government, Financial and technical capacity of contractors to complete and handover the project within the agreed period of time, among others.

Based on the result obtained and the conclusion drawn from the study, due attention should be given by the government on the budget of those activities dropped suddenly without a plan after the budget was allocated to universities. The government should apply Block grant budget ${ }^{1}$ system for public Universities especially for the capital budget to utilize the approved budget effectively on those projects which have the best performance during the fiscal budget year. Because some activities are consuming more budget than allocated and some are less due to different external factors and Implementation of projects was found to be limited by this red tape and if the same is reduced, then the success of budget utilization will be increased. So, the potential of the contractor both technical and financial capacity and their past performance should be evaluated before coming to an agreement and there should be a need timely and continuous follow up of the progress of the project and take corrective action before the end of the fiscal budget year.

\section{REFERENCES}

> Abdu M. (2014).Government Expenditure Management and Control in Ethiopia. Research Journal of Finance and Accounting, Vol.5, No.11, 2014

$>$ Ahmad, A., Farley, A., and Naidoo, M. (2012). Analysis of Government-University Relationship from the Perspective of Agency Theory. Journal of Education and Practice, Vol. 3, No 6, 2012.

$>$ Alemayehu, G. and Dawit, B. (2011). Spending without proper planning: Why Ethiopian Agriculture is not growing despite High Public Spending in the Sector by Africa Standard, A Macro Perspective. IAES Working Paper Serious NO. A10/2011

$>$ Arora M. 2010. Management Accounting. Theory, Problems, and Solutions. Himalaya publishing house: Delhi.

$>$ Federal Democratic Republic of Ethiopia (FDRE). 2012. Growth and Transformation Plan (2010/11-2014/15)

$>$ Federal Democratic Republic of Ethiopia (FDRE). 2014. Growth and Transformation Plan Annual Progress Report for F.Y.2012/13: Ministry of Finance and Economic Development. February 2014, Addis Ababa, Ethiopia.

$>$ The Federal Democratic Republic of Ethiopia. FDRE. 2009. The Federal Government of Ethiopia Financial Administration Proclamation No. 190/2010.Federal NegaritGazeta.15th Year, No. 56, 6th August 2009, Addis Ababa, Ethiopia.

$>$ Global University Network for Innovation. 2009. Higher education at a time of transformation: New dynamics for social responsibility, GUNI/Palgrave Macmillan: Basingstoke.

$>$ Gyimah-Brempong, K. (1998). The Political Economy of Budgeting in Africa: 1971-1991.Journal of Public Budgeting, Accounting, and Financial Management.

$>$ Khan, A. and Hildreth, B. W.(ed.). 2002. Budget theory in the public sector. QUORUM BOOKS.

$>$ Lewis, C.W. .2007. How to read a Local budget and assess performance. In. anwar, S. (ed.)

$>$ Liefner I. (2003). Funding, resource allocation, and performance in higher education systems: Journal of Higher Education vol. 46.

$>$ MoFEC 2010. Program Budget Training Module: Ministry of Finance and Economic Cooperation, Ethiopia

$>$ Motwani, D., Shrimali, D. \& Agarwal, k. (2014).Customers ${ }^{\text {ee }}$ Attitude towards Social Media

$>$ Omitoogun W. \& Hutchful E. (eds) (2006). Budgeting for the Military Sector in Africa:The Processes and Mechanisms of Control, Oxford University Press.

$>$ Pongsena, S.(2014). A Follow-Up Study of Bachelor of Science Graduates in applied statistics from SuanSunandHaRajabhat University during the 1999-2012 academic years. International Journal of Social, Education, Economics, and Management.

$>$ Rotich K. and Ngahu S. 2015. Factors Affecting Budget Utilization Kericho Country Government in Kenya: International Journal of Economics, Commerce, and Management, United Kingdom Vol. III, Issue 6, June 2015.

$>$ Shah A. (ed.). 2008. Budgeting and Budgetary Institutions. The World Bank: Washington, D.C.

$>$ The World Bank. 1998. .Public Expenditure Management Hand Book.The International Bank for Reconstruction and Development/ THE WORLD BANK: Washington, D.C. 20433, U.S.A.

\footnotetext{
${ }^{1}$ A Block Grant is money that is awarded, or granted, by a national government to state and government offices. Block grants are earmarked for a specific project or projects, and typically there are guidelines as to how the money can be spent. Block grants have less oversight from the federal government and provide flexibility to each University in terms of designing and implementing programs.
} 